\title{
Rare and dangerous complication of nasogastric tube insertion
}

\author{
Tze Hao Leow, ${ }^{1}$ Stephen Lam, ${ }^{2}$ Bhaskar Kumar ${ }^{3,4}$
}

${ }^{1}$ General Surgery, Norfolk and Norwich University Hospital NHS Trust, Norwich, UK

${ }^{2}$ General Surgery, Wexham Park Hospital, Slough, UK

${ }^{3}$ Upper Gastrointestinal Surgery, Norfolk and Norwich University Hospital NHS Trust, Norwich, UK ${ }^{4}$ Faculty of Medicine and Health Sciences, University of East Anglia, Norwich, UK

\section{Correspondence to}

Mr Stephen Lam;

stephenjosephlam@yahoo.co.uk

Accepted 8 May 2020

\section{DESCRIPTION}

A 72-year-old woman presented to an academic teaching hospital with a 2-day history of dyspnoea following 2 months of worsening dysphonia and oropharyngeal dysphagia. On examination, she had stridor and expiratory wheeze. Medical history included marked kyphoscoliosis with limited neck extension as well as venous leg ulcers, osteoporosis, atrial fibrillation and anaemia. She was an ex-smoker, with 50 pack years. Due to respiratory instability, she was admitted to the intensive care unit and urgent referral made to the ear, nose and throat team. A fibreoptic nasendoscopy demonstrated bilateral abductor vocal cord palsy. A surgical tracheostomy was inserted, and due to concerns about the safety of her swallow, a decision was made to place a fine bore nasogastric $(\mathrm{NG})$ feeding tube at the bedside. During NG insertion, there was a significant amount of resistance felt at $20 \mathrm{~cm}$ from the incisiors. Despite this, NG tube placement was completed uneventfully. A CT of the neck and thorax was arranged to investigate the cause of the vocal cord palsy.

The CT neck and thorax showed gas within the oesophageal wall and tracking along the line of the oesophagus to the diaphragm. There was also gas within the mediastinum but no fluid collection. Due to concerns of an iatrogenic oesophageal perforation during NG insertion, an urgent referral to the oesophagogastric on call consultant was made. The patient did not show any signs of sepsis, or surgical emphysema. On ITU, an emergency oesophagogastroduodenoscopy was performed. At $20 \mathrm{~cm}$ from the incisors, a haematoma and a mucosal flap

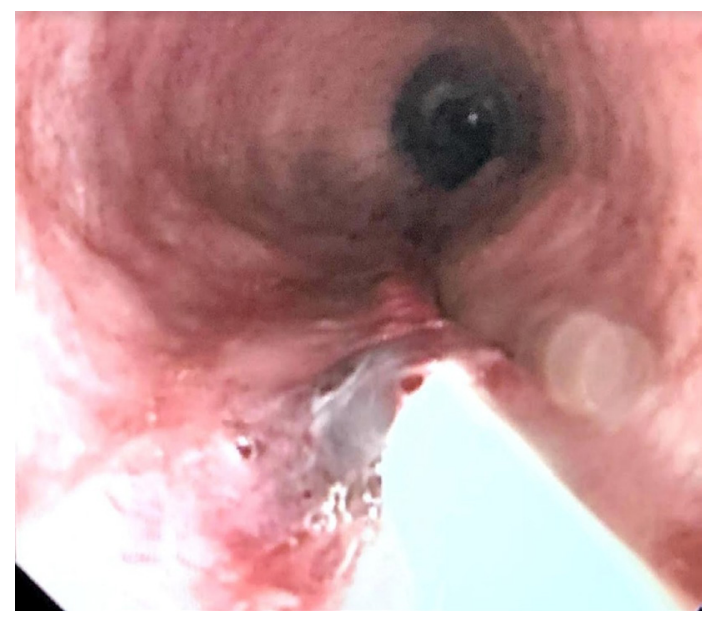

Figure 1 An image captured during oesophagogastroduodenoscopy showing a haematoma and mucosal flap at $20 \mathrm{~cm}$ from the incisors.

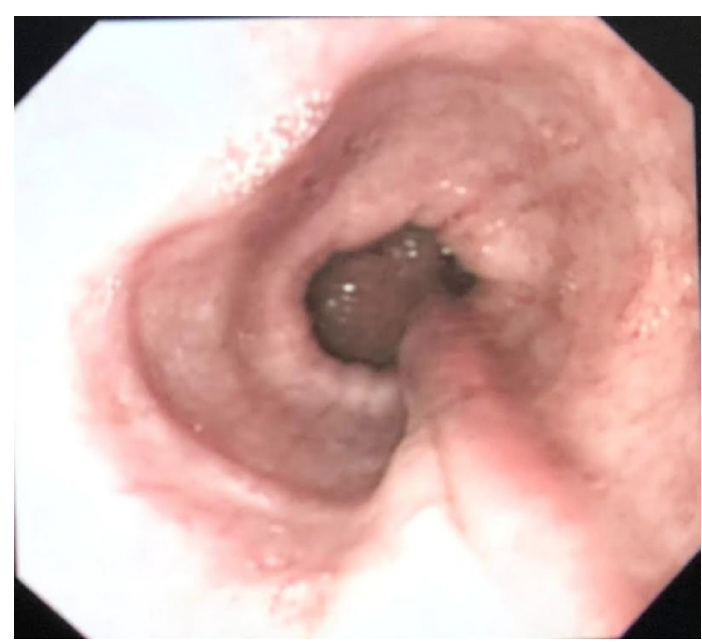

Figure 2 An image captured during oesophagogastroduodenoscopy showing that the nasogastric tube was seen to tunnel under the mucosa down to the oesophagogastric junction.

(figure 1) were seen, below which, the NG tube was seen to tunnel under the mucosa down to the oesophagogastric junction (figure 2). On removing the tube, a mucosal defect was seen, but there was no obvious full thickness perforation. A decision was made to treat the patient for a potential full thickness perforation even though this was not evident endoscopically. Therefore, an endoluminal nasojejunal (NJ) feeding tube was inserted under direct vision for nutrition and a $14 \mathrm{Fr}$ NG tube was placed for drainage and secured. The patient was managed with nil by mouth, $\mathrm{NJ}$ feeding at a rate of $20 \mathrm{~mL} /$ hour, intravenous piperacillin tazobactam, fluconazole and omeprazole. The patient made an uneventful recovery from the iatrogenic injury and was managed on a neurological ward. Her underlying diagnosis was acute bulbar palsy variant of Guillain-Barré syndrome from which she made a slow but full recovery.

Submucosal tunnelling or intramural oesophageal dissection due to blind NG insertion is a very rare complication. We identified eight such cases in the literature, ${ }^{1-8}$ with a median patient age of 48 years (range 26-78 years) and a female-to-male ratio of $3: 1$. Symptoms of oesophageal dissection included sudden onset of chest pain, odynophagia, dysphagia and mild or no haematemesis. Management was usually conservative with recovery in most cases. However, more invasive treatment such as the application of clips endoscopically ${ }^{2}$ or even total gastrectomy ${ }^{3}$ was reported. Overall, mortality 
was high at $25 \%$, representing a rare and dangerous complication of a commonly performed procedure.

Risk factors for oesophageal perforation include underlying oesophageal disease (eg, oesophagitis, strictures, malignancy), cervical spine disease and advanced age, with recent midfacial trauma or surgery being an absolute contraindication to NG insertion. ${ }^{9}$ Of the few reported cases of oesophageal submucosal dissection, risk factors included: neurological disease (stroke, ${ }^{1}$ brain tumour, ${ }^{3}$ Guillain-Barré (present case)), abnormal

\section{Learning points}

- Recognition of a high-risk patient is of vital importance in performing all bedside procedures including nasogastric (NG) tube placement. This patient was an elderly woman with neurological disease affecting her swallow and severe kyphoscoliosis and reduced neck mobility.

- A sensation of resistance should alert the clinician to nonluminal positioning. This is particularly important in the context of using a relatively stiff fine bore feeding tube which has a metallic guidewire. Blindly proceeding in the presence of resistance is not advisable.

- A low threshold needs to be applied for early imaging, including direct visualisation of the oesophagus if there are concerns of oesophageal trauma with NG insertion.

- Conservative management is suitable for patients who are stable with no signs of deterioration suggestive of perforation. However, in cases with evidence of sepsis or severe pain, endoscopic or surgical management may be considered. gastrointestinal anatomy (gastric tumour, ${ }^{2}$ oesophagitis, ${ }^{5}$ impacted food bolus ${ }^{6}$ ) intubated patients ${ }^{4}{ }^{8}$ and patients with symptoms of dysphagia of any cause. ${ }^{136}$

Contributors BK and SL: conception and design. THL and SL: acquisition of data and drafting of the study. All authors discussed the planning and conduct of the study. All authors contributed to the analysis and interpretation of the data. All authors contributed to critical revisions of the study and agreed on the final draft.

Funding The authors have not declared a specific grant for this research from any funding agency in the public, commercial or not-for-profit sectors.

Competing interests None declared.

Patient consent for publication Obtained.

Provenance and peer review Not commissioned; externally peer reviewed.

\section{REFERENCES}

1 Le Mouel J-P, Basile P, Gonzalez J-M, et al. Double lumen esophagus due to false submucosal path induced by nasogastric tube: endoscopic treatment with marsupialization. Endoscopy 2018;50:E325-6.

2 Abe S, Minagawa T, Tanaka H, et al. Successful endoscopic closure using over-the-scope clip for delayed stomach perforation caused by nasogastric tube after endoscopic submucosal dissection. Endoscopy 2017:49:E56-7.

3 Nejo T, Oya S, Tsukasa T, et al. Limitations of routine verification of nasogastric tube insertion using X-ray and auscultation: two case reports of life-threatening complications. Nutr Clin Pract 2016;31:780-4.

4 Esophagus. Am J Gastroenterol 2014;109 Suppl 2:S1-39.

5 Yang C-W, Yen H-H, Su W-W, et al. Esophageal submucosal tunnel: a rare complication of nasogastric tube placement. Dis Esophagus 2016:29:690.

6 Hutchinson R, Ahmed AR, Menzies D. A case of intramural oesophageal dissection secondary to nasogastric tube insertion. Ann R Coll Surg Engl 2008;90:4-7.

7 Hsu CC, Changchien CS. Endoscopic and radiological features of intramural esophagea dissection. Endoscopy 2001;33:379-81.

8 Lind LJ, Wallace DH. Submucosal passage of a nasogastric tube complicating attempted intubation during anesthesia. Anesthesiology 1978;49:145-7.

9 Bhatia NL, Collins JM, Nguyen CC, et al. Esophageal perforation as a complication of esophagogastroduodenoscopy. J Hosp Med 2008;3:256-62.

Copyright 2020 BMJ Publishing Group. All rights reserved. For permission to reuse any of this content visit

https://www.bmj.com/company/products-services/rights-and-licensing/permissions/

BMJ Case Report Fellows may re-use this article for personal use and teaching without any further permission.

Become a Fellow of BMJ Case Reports today and you can:

- Submit as many cases as you like

- Enjoy fast sympathetic peer review and rapid publication of accepted articles

- Access all the published articles

- Re-use any of the published material for personal use and teaching without further permission

Customer Service

If you have any further queries about your subscription, please contact our customer services team on +44 (0) 2071111105 or via email at support@bmj.com.

Visit casereports.bmj.com for more articles like this and to become a Fellow 